«Системні технології» 5 (136) 2021 «System technologies»

DOI 10.34185/1562-9945-5-136-2021-08

УДК 519.2:004.9

Л.О. Кіріченко, Є.Д. Степаненко, Д.Є. Яндуков

\title{
КЛАСИФІКАЦІЯ ЧАСОВИХ РЯДІВ ІЗ ВИКОРИСТАННЯМ РЕКУРЕНТНИХ ДІАГРАМ
}

Анотація. У статті описано новий підхід до класифікації часових рядів на основі їх візуалізації. Часовий ряд подається у вигляді чорно-білого зображення своєї рекурентної діаграми. В якості класифікатора зображень використовується згорткова нейронна мережа. Даними для класифікації є реалізації електрокардіограм, які містять записи здорових людей та пацієнтів з діагнозом ішемія. Результати досліджень вказують на добру точність класифікації порівняно з іншими методами та потенційні можливості цього niдxодy.

Ключові слова: класифікація, часовий ряд, рекурентна діаграма, згорткова нейронна мережа.

Вступ і мета. В даний час для класифікації часових рядів широко використовується машинне навчання. Найчастіше, після попередньої обробки часового ряду, з нього витягується набір деяких ознак, які подаються на вхід класифікатора. У той же час в останні десятиліття широке поширення набули методи аналізу часових рядів, які базуються на методах хаотичної динаміки. Одним 3 методів, що беруть початок в нелінійної динаміки, є рекурентний аналіз (метод рекурентних діаграм), спочатку запропонований в [1], який набув широкого поширення і розвиток, зокрема, в роботах [2,3]. Рекурентна діаграма містить інформацію про повторюваності станів динамічної системи, представленої часовим рядом. Рекурентні властивості можна візуалізувати у вигляді геометричних структур і наочно уявити динаміку ряду. Таким чином метод рекурентних діаграм перетворює часові ряди в зображення, які можна класифікувати методами комп'ютерного зору [4-6].

Метою представленої роботи є проведення класифікації електрокардіографічних реалізацій (ЕКГ) на основі візуалізації рекурентних діаграм за допомогою згорткової нейроної мережі. ЕКГ широко використовуєть для функціонального дослідження серцево-судинної системи і своечасне виявлення захво-

(C) Кіріченко Л.О., Степаненко Є.Д., Яндуков Д.Є., 2021 


\section{«Системні технології» 5 (136) 2021 «System technologies»}

рювання за даними ЕКГ відіграє важливу роль в запобіганні серцево-судинних хвороб.

Рекурентні діаграми. Рекурентний аналіз є методом нелінійної динаміки, що використовуються для виявлення неочевидних залежностей в динаміці ряду та базується на фундаментальній властивості дисипативних динамічних систем - рекурентності (повторюваності станів).

Нехай точка $x(i)$ відповідає $i$-й точці фазової траєкторії, що описує обрану динамічну систему у $m$-мірному просторі, для $i=1, \ldots, N$, тоді рекурентна діаграма є матрицею точок $N \times N$, де ненульовий елемент з координатами $(i, j)$ відповідає випадку, коли $x(j)$ достатньо близько до $x(i)$. Іншими словами, рекурентними є стани $x_{j}$, які потрапляють в $m$-вимірну околицю з радіусом $\varepsilon$ і центром в $x_{i}$. Ці точки $x_{j}$ називаються рекурентними. Довільно взята рекурентна точка не несе якої-небудь корисної інформації про стани в часи $i$ i $j$. Тільки вся сукупність рекурентних точок дозволяє відновити властивості системи [1,2].

Згорткові нейронні мережі. Згорткова нейронна мережа являє собою особливу архітектуру штучних нейронних мереж, націлену на ефективне розпізнавання образів. Згортка - це лінійне перетворення, що застосовується до квадратного вікна та плавно переміщується по вхідним даним, при цьому пікселі з вікна скалярно перемножуються на матрицю згортки.

Ідея сверточних нейронних мереж полягає в чергуванні згорткових, субдискретизуючих і звичайних шарів нейронної мережі. Структура мережі $є$ односпрямованою (без зворотного зв'язку), принципово багатошаровою. Для навчання використовуються стандартні методи, найчастіше метод зворотного поширення помилок. Функція активації нейронів може бути різною, залежно від завдання. Архітектура мережі отримала свою назву через операцію згортки, суть якої полягає в тому, що кожен фрагмент зображення множиться на матрицю (ядро) елемента згортки, а результат підсумовується і записується в одну і ту ж позицію в вихідне зображення [7,8].

Мережа працює наступним чином. Зображення проходить через ряд згорткових, нелінійних шарів, шарів, що об'єднують та повнозв'язних шарів та генерується висновок. Висновок може бути меткою класу або ймовірністю класів, які найкраще описують зображення. 


\section{«Системні технології» 5 (136) 2021 «System technologies»}

Перший шар в мережі завжди є згортковим. Це набір функціональних карт однакового розміру. Кожна карта має синаптичне ядро, яке є вікном, яке ковзає по всій області попередньої карти і знаходить певні ознаки об'єктів.

Нейрони на першому згортковому шарі не пов'язані з кожним пікселем вхідного зображення, а тільки з пікселями у власних рецепторних полях. У свою чергу нейрон на другому згортковому шарі пов'язаний тільки з нейронами, які знаходяться всередині невеликого прямокутника в першому шарі. Така архітектура дозволяє мережі зосередитися на низькорівневих ознаках в першому прихованому шарі, щоб далі компонувати їх в ознаки більш високого рівня.

Вихід першого рівня є вхідним значенням другого рівня. Після застосування набору фільтрів після першого шару будуть активовані фільтри, які представляють властивості вищого рівня. Чим більше згорткових шарів проходить зображення, і чим далі воно переміщається по мережі, тим складніші характеристики відображаються на картах об'єктів.

Після згорткових шарів йде шар, що об'єднує, основне завдання якого прорідити вхідне зображення для зменшення обчислювального навантаження, витрат пам'яті і кількості параметрів, зменшуючи ризик перенавчання.

Останній тип шару - це шар звичайного багатошарового персептрона. Метою шару є класифікація, він моделює складну нелінійну функцію, оптимізація якої підвищує якість розпізнавання. Вихідний шар пов'язаний з усіма нейронами попереднього шару. Кількість нейронів відповідає кількості розпізнаних класів.

Опис експеріменту і результати. Для обчислювального експерименту було обрано датасет з часовими рядами з репозиторію «UEA \& UCR Time Series Classification Repository», назва датасету - «ECG200» [9].

В ньому містяться медичні часові ряди, що отримані з електрокардіограми. Ряди розбиті на два класи: «норма» та «ішемія», що показано на рис. 1 [9]. В датасеті є 200 виборок: 100 для тренування класифікатора та 100 для перевірки. В кожному часовому ряду по 100 значень. Кожний часовий ряд простежує електричну активність, записану під час серцебиття.

Отже, ми маємо задачу бінарної класифікації медичних часових рядів. Виконаємо класифікацію рядів за їхними рекурентними діаграмами. На рис. 2 наведено приклади часових рядів з датасету, а на рис. 3 наведено приклади відповідних рекурентних діаграм. 


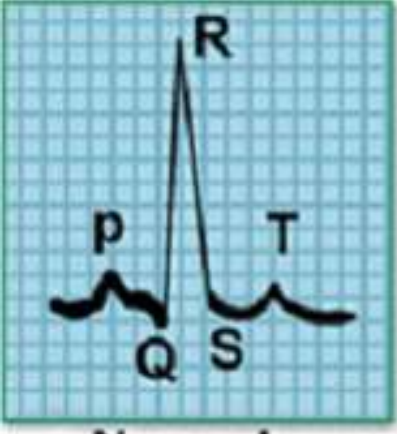

Normal

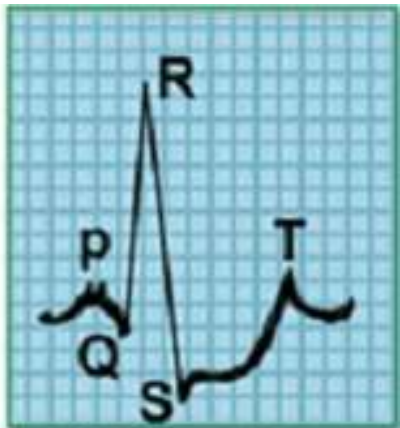

Ischemia

Рисунок 1 - ЕКГ, «норма» та «ішемія»

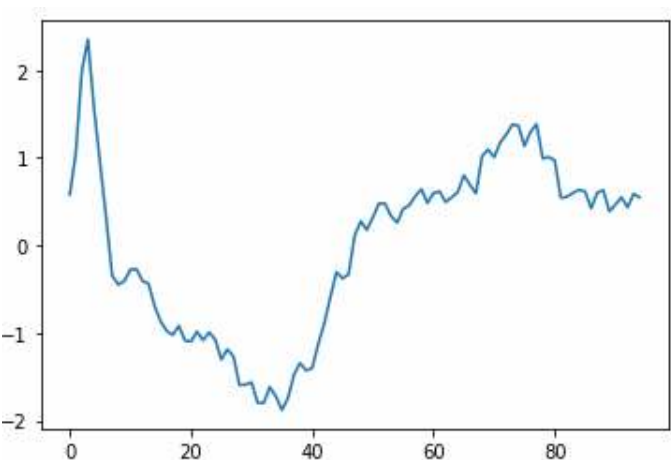

a)

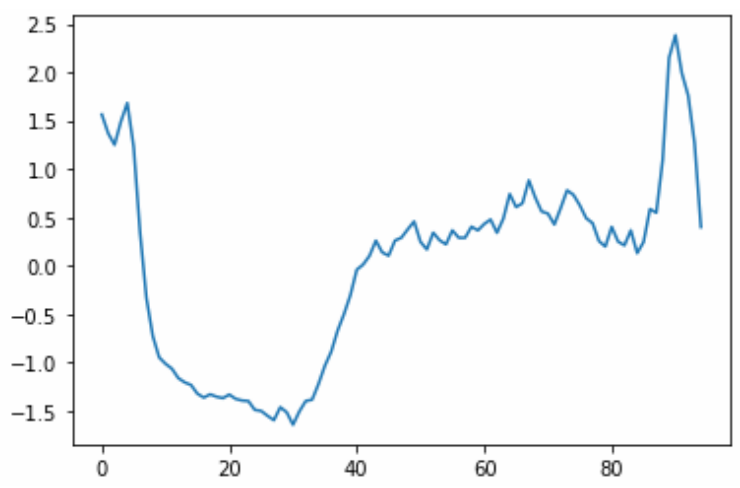

б)

Рисунок 2 - Приклади часових рядів а) клас «норма»; б) клас «ішемія».

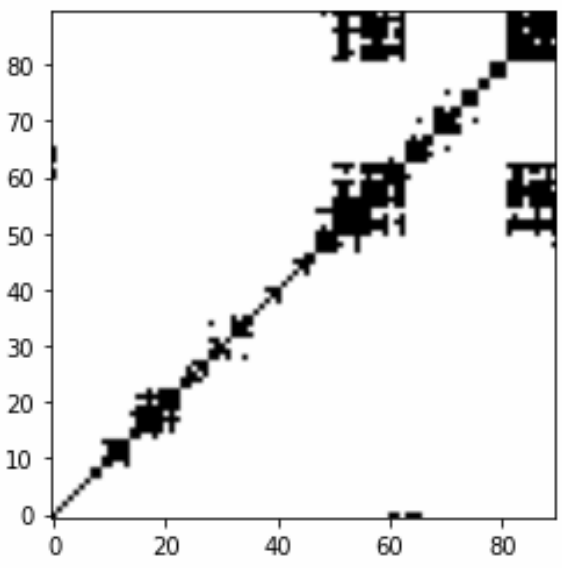

a)

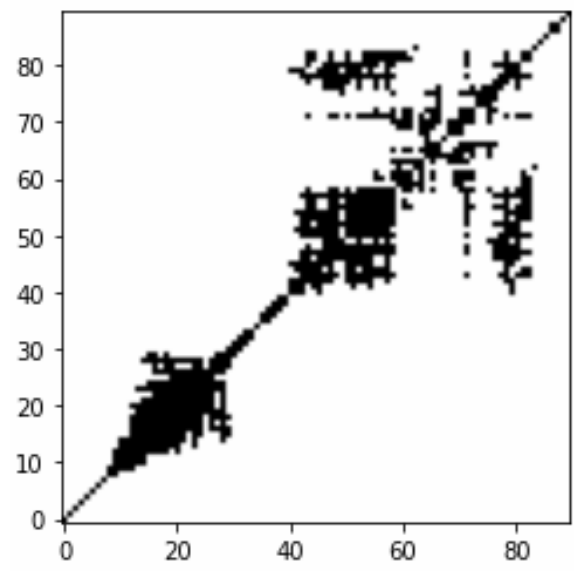

б)

Рисунок 3 - Рекурентні діаграми а) клас «норма»; б) клас «ішемія

Для проведення класифікації була вибрана мова Python. Python - це об'єктно-орієнтована мова програмування високого рівня. Це мова з відкритим кодом, що містить багато бібліотек для обробки і графічного зображені вання даних. Python відноситься до найбільш затребуваних і популярнних мов програ- 
«Системні технології» 5 (136) 2021 «System technologies»

мування, про що свідчать численні рейтинги та аналіз пропозицій на ринку розробки програмних продуктів [10].

Вхідні часові ряди ЕКГ для навчальної та тестової вибірки були перетворені в зображення рекурентних діаграм, які класифікувались за допомогою нейронної мережі. Для створення нейронної мережі була використана бібліотека «Keras», яка $є$ найпопулярнішою для створення нейронних мереж. Розроблена згорткова нейронна мережа містить вісім шарів. Нелінійна фнкція ReLU застосовується до вихідних даних кожного згорткового і повнозв'язну шару. В якості методу навчання був обраний метод стохастичної оптимізації ADAM.

Точність результвтів класифікації різними метриками наведена у таблиці 1.

Таблиця 1

Точність класифікатора різними метриками

\begin{tabular}{|c|c|c|c|}
\hline & Precision & Recall & F1-score \\
\hline Class 0 & 0,93 & 0,72 & 0,81 \\
\hline Class 1 & 0,86 & 0,97 & 0,91 \\
\hline Accuracy & & & 0,88 \\
\hline
\end{tabular}

Точність класифікатора із застосуванням рекурентних діаграм сягнула 88\%. Слід зазначити, що в описі набору даних було вказано, що найкраща точність класифікації цих даних була отримана за допомогою класифікатора Bagof-SFA-Symbols (BOSS) і дорівнювала 89\% [9]. Хоча точність нашого класифікатора дещо менша, ми використовували просту нейронну мережу. Очевидно, що при використанні глибокої нейронної мережі, спрямованої на розпізнавання чорно-білих зображень, точність класифікації буде вище.

Висновки. У статті обговорювався метод класифікації часових рядів, заснований на розпізнаванні чорно-білих зображень. Як зображення, що відповідають часовим рядам, використовувались їхні рекурентні діаграми.

Вхідними даними для експерименту були часові ряди ЕКГ, що містили 100 значень, які були розділені на два класи: «нормальний» та «ішемія». Класифікація зображень проводилася за допомогою згорткової мережі.

Класифікація ЕКГ дозволяє виявити взаємозв'язок між її характеристиками і видом захворювання і запропонувати найбільш ефективний спосіб діагностування. 


\section{«Системні технології» 5 (136) 2021 «System technologies»}

\section{REFERENCES}

1. Eckmann, J. P., Kamphorst, S. O., Ruelle, D.: Recurrence plots of dynamical systems. Europhysics Letters 4(9), 973-977 (1987).

2. Marwan, N., Wessel, N., Meyerfeldt, U., Schirdewan, A., Kurths, J.: Recurrenceplots-based measures of complexity and application to heart-rate-variability data. Physical Review E 66(2), 026702-1-026702-6 (2002).

doi: 10.1103/PhysRevE.66.026702

3. Marwan, N., Romano, M. C., Thiel, M., Kurths, J.: (2007). Recurrence plots for the analysis of complex systems. Physics reports 438(5-6), 237-329 (2007).

4. Kirichenko, L., Radivilova, T., Bulakh, V.: Classification of fractal time series using recurrence plots. In 2018 International Scientific-Practical Conference Problems of Infocommunications. Science and Technology (PIC S\&T) 2018 October, Kharkiv, Ukraine, IEEE, 719-724 (2018). doi: 10.1109/INFOCOMMST.2018.8632010

5. Kirichenko L., Zinchenko P., Radivilova T., Tavalbeh M. Machine Learning Detection of DDoS Attacks Based on Visualization of Recurrence Plots. Conflict Management in Global Information Networks (CMiGIN 2019): Proceedings of the International Workshop, Kyiv, Ukraine. Ceur, 2019. P. 23-34.

6. Kirichenko L., Zinchenko P., Radivilova T. Classification of Time Realizations Using Machine Learning Recognition of Recurrence Plots. In: Babichev S., Lytvynenko V., Wójcik W., Vyshemyrskaya S. (eds) Lecture Notes in Computational Intelligence and Decision Making. ISDMCI 2020. Advances in Intelligent Systems and Computing, 2021, vol 1246. Springer, Cham, pp. 687-696.

https://doi.org/10.1007/978-3-030-54215-3_44.

7. Y. LeCun and Y. Bengio: Convolutional Networks for Images, Speech, and TimeSeries, in Arbib, M. A. (Eds), The Handbook of Brain Theory and Neural Networks, MIT Press, 1995

8. Ciresan, Dan; Ueli Meier; Jonathan Masci; Luca M. Gambardella; Jurgen Schmidhuber "Flexible, High Performance Convolutional Neural Networks for Image Classification" Proceedings of the Twenty-Second International Joint Conference on Artificial Intelligence-Volume 2: 1237-1242. 2013

http://people.idsia.ch/ juergen/ijcai2011.pdf last accessed 2019/08/20

9. Time series classification, http://www.timeseriesclassification.com last accessed 2019/28/0216

10. D. Cielen, A. Meysman, M. Ali Introducing Data Science: Big Data, Machine Learning, and more, using Python tools, Manning Publications, 2016, 325 p. 
«Системні технології» 5 (136) 2021 «System technologies»

Класифікація часових рядів із використанням рекуррентних діаграм

у статті описано новий підхід до класифікації часових рядів на основі їх рекурентних діаграм. В якості класифікатора зображень використовується згорткова нейронна мережа. Даними для класифікації є реалізації електрокардіограм. Результати досліджень вказують на добру точність класифікації порівняно з іншими методами та потенційні можливості цього підходу.

\section{Time series classification using recurrence charts}

The article describes a new approach to the classification of time series based on their recurrence plots. A convolutional neural network is used as an image classifier. The data for classification are the realizations of electrocardiograms. Research results indicate good classification accuracy compared to other methods and the potential of this approach.

Кіріченко Людмила Олегівна - д.т.н., професор кафедри прикладної математики Харківського національного університету радіоелектроніки.

Степаненко Євгенія Дмитровна - магістрантка кафедри прикладної математики Харківського національного університету радіоелектроніки.

Яндуков Дмитро Євгенович - аспирант кафедры прикладной математики Харьковского национального университета радиоэлектроники.

Кириченко Людмила Олеговна - д.т.н., профессор кафедры прикладной мате-матики Харьковского национального университета радиоэлектроники.

Степаненко Евгения Дмитровна - магистрантка кафедры прикладной математики Харьковского национального университета радиоэлектроники.

Яндуков Дмитрий Евгеньевич - аспирант кафедры прикладной математики Харьковского национального университета радиоэлектроники.

Kirichenko Lyudmila Olegovna - Doctor of Technical Sciences, Professor of the Department of Applied Mathematics, Kharkiv National University of Radio Electronics.

Stepanenko Evgeniya Dmitrovna - Master's student of the Department of Applied Mathematics, Kharkiv National University of Radio Electronics.

Yandukov Dmitry Evgenievich - postgraduate student of the Department of Applied Mathematics, Kharkiv National University of Radio Electronics. 